\title{
Arthroscopic Removal of Palmar/Plantar Osteochondral Fragments (POF) in the Metacarpo- and Metatarso-Phalangeal Joints of Standardbred Trotters - Outcome and Possible Genetic Background to POF
}

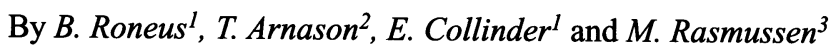 \\ ${ }^{1}$ Department of Surgery and Medicine, Swedish University of Agricultural Sciences, Uppsala, ${ }^{2}$ International \\ Horse Breeding Consultant, Morgongåva, and ${ }^{3}$ Department of Genetics, University of Umeå. Umeå, Sweden.
}

\begin{abstract}
Roneus B, Arnason T, Collinder E, Rasmussen M: Arthroscopic removal of palmar/plantar osteochondral fragments (POF) in the metacarpo- and metatarsophalangeal joints of standardbred trotters, outcome and possible genetic background to POF. Acta vet. scand. 1998, 39, 15-24. - A clinical material of 133 Standardbred horses with palmar/plantar osteochondral fragments (POF) in the metacarpo- and metatarsophalangeal joints were studied. All horses had their fragments removed with arthroscopic surgery. 102 of the horses were 3 years old or younger when surgery was performed. Anatomical localisations of the fragments were in agreement with earlier reports. There was no statistical significant difference in month of birth in the POF- group compared to the total population. Eighty $\%$ of the horses that had raced before surgery came back to racing. The racing performance relative to their contemporaries remained the same after the POF operation. $65 \%$ of the horses that had not raced before surgery raced after the operation. The breeding index BLUP (Best Linear Unbiased Prediction) was used to evaluate if the POF- horses differed genetically in racing ability from the total population. The average BLUP value of the POF group was 103.4 $( \pm 0.65)$, while the mean BLUP value of the total population was 98.9. This difference was highly significant and indicated that these POF horses belonged to a selected group. A homogeneity test of allele frequencies in blood type systems was performed to evaluate if any genetic difference was persistent between POF horses compared to the total population. The statistical analysis of gene frequencies for alleles in blood type systems indicated a genetic discrimination in blood type systems $\mathrm{D}$ and Tf.
\end{abstract}

horse; arthroscopy; BLUP; blood group.

\section{Introduction}

Palmar/plantar intraarticular osteochondral fragments (POF) in the fetlock joints are common in Standardbred horses. The incidence of POFs in the Standardbred population is reported to be 12\%-28.8\% (Sandgren 1988, Roneus \& Carlsten 1989, Gröndahl 1992). Their clinical significance has been disputed. Opinions range from that they are incidental findings with no clinical relevance to cases where the fragments are considered to cause joint lameness. Different etiological theories have been proposed. The fragments have been considered 
to be avulsion fractures (Birkeland 1972), a part of the osteochondrosis syndrome (Sönnichsen et al. 1982), or a result of biomechanical stress in the fetlock area (Dalin et al. 1993). POFs develop early in life and can be radiologically detected in foals before 5 months of age (Carlsten et al. 1993). Previous studies have reported a higher incidence of POFs in horses born in the summer (June-August) compared to horses born in early spring (February-April) (Philipsson et al. 1993).

POFs are located intraarticularly, attached to and embedded in the joint capsule in the space between the palmar/plantar joint surface of the first phalanx and the base of the sesamoid bones. The fragments can be unilateral, medial or lateral, or bilateral within the same joint.

The uncertainty of the clinical significance of osteochondral fragments detected on radiographs in the joints of healthy young horses without any signs of lameness raises problems for horse owners, trainers and veterinarians involved in purchase examination, insurance and in questions of breeding, heritability and future racing performance.

A possible genetic background for POF has been much discussed, but no regular hereditary transmission has been indicated. One way to investigate genetically complex trait is to search for associations with alleles in polymorphic marker systems.

The aim of this study was to statistically study the racing performance and breeding index Best Linear Unbiased Prediction (BLUP) in Standardbred horses with POFs and to evaluate the outcome after arthroscopic removal of the fragments. The aim was also to determine if horses with POFs were genetically different from the normal population of Standardbred trotters.

\section{Materials and methods}

The material consisted of 133 clinical cases of
Standardbred horses with POFs that were arthroscopically removed at the Department of Surgery and Medicine, Swedish University of Agricultural Sciences during 1988-1993. The majority of the horses were referred to the clinic for surgery after clinical and radiological examination (Fig. 1A and Fig. 1B). All horses were operated by the same surgeon (B. R.). This group of horses was compared with the total population of Standardbred trotters in Sweden.

\section{Surgical technique}

All horses were operated in lateral recumbency under general anaesthesia. The arthroscopic technique for removal of unilateral fragments has previously been described (McIlwraith 1990, Houttu 1991). All operated horses were recommended a convalescence period with daily hand walking for 6 weeks.

The technique for removal of bilateral fragments, 2 fragments, located both medially and laterally within the same joint, was based on the technique for removal of one fragment. But the arthroscopic insertion was created about one $\mathrm{cm}$ more proximal than usual in order to get a better overview when removing the second fragment located on the other side of the joint. After removal of the first fragment, a second instrumental portal was created on the opposite side of the joint in order to reach the fragment while the arthroscope was in its original portal but just slid deeper into the joint to visualise the opposite side. This technique makes it possible to remove both fragments without turning the horse over on the other side.

No adverse reactions such as permanent joint swelling, infection or increased lameness due to the surgery were seen in any of the horses.

\section{Month of birth}

To investigate if month of birth was associated with POFs in this material, a $\chi^{2}$-test was per- 


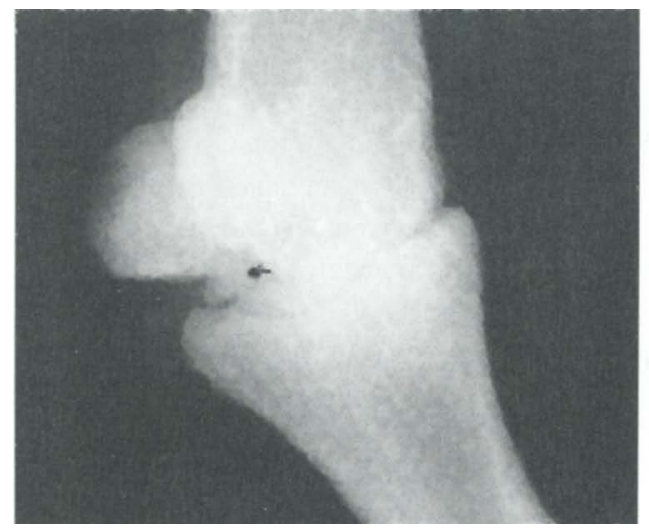

Figure 1A. Dorsoproximal medial-plantarodistal lateral oblique (D35Pr45M-PIDiLO) view of the metatarsophalangeal joint showing a typical plantar osteochondral fragment (POF).

formed on frequencies of birth per month. The month of birth for 131 out of the 133 horses in this material was known at the register of Standardbreds at the Swedish Trotting Association and was compared with the total population. A sample group was randomly selected from the total population of Swedish Standardbred trotters; every 24th registered Standardbred born in Sweden 1976-1986 (2583 horses).

\section{Racing performance}

Many racing performance traits exhibit skewed distributions (Arnason 1994). Mathematical transformations can in many cases be applied in order to obtain approximate normal distributions of racing variables, however. A special normally distributed racing performance index was constructed in order to get a standardised normally distributed measure of annual racing performance of any individual horse compared to its contemporaries of the same sex. The racing variables were transformed according to $\mathrm{Ar}$ nason et al. (1982).

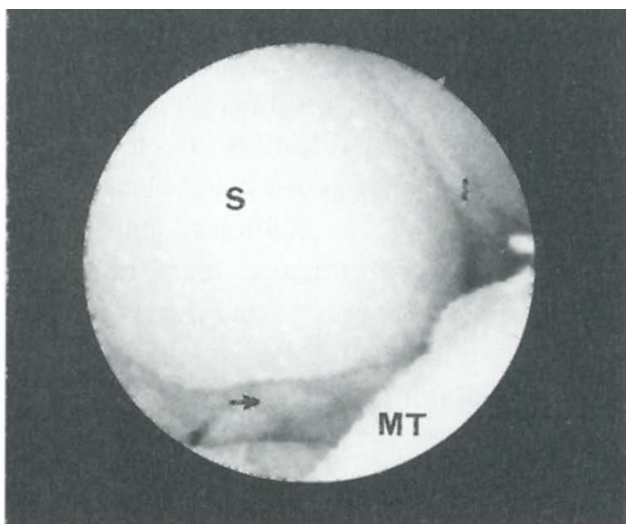

Figure 1B. Arthroscopic view before surgical removal of a POF (arrow) in situ similar to that that is radiographically shown in Fig. 1A, S: The articular surface of the medial sesamoid bone. I: The intersesamoidean ligament. MT: The articular surface of the plantar metatarsus.

The annual performance index of the $\mathrm{k}_{\mathrm{th}}$ horse was computed as:

$$
\begin{gathered}
I_{k}=\left(\left(x_{1}+x_{2}+x_{3}-x_{4}\right) / 4\right) \cdot 10+100, \\
\text { where } x_{i}=\left(y_{i j k}-\mu_{i j}\right) / \sigma_{i j},
\end{gathered}
$$

and the subscripts $i$ represent the racing variables: $1=(\% \text { placed } 1-3)^{1 / 2} ; 2=(\text { earnings })^{1 / 4}$; $3=\log _{10}\left(\left(\right.\right.$ earnings $\left.{ }^{1 / 2}\right) /$ number of starts +1$)$; $4=\log _{10}$ (best racing time $-1 \mathrm{~min}$.) and $j$ represents sex/birth-year subclass.

In order to evaluate the effects of POF-operation on racing performance, the annual performance indexes before and after operation were compared using a simple Student's $t$ test. In this computation only the POF-operated horses that had completed at least 5 races during the year were included.

\section{Best Linear Unbiased Prediction (BLUP)}

Genetic evaluations of 6 racing variables in 3-5 year-old Swedish standardbred trotters, born 1976 to 1991 , were computed according to 
multiple trait BLUP animal model (Henderson $\&$ Quaas 1976). The procedure has been used routinely since 1992 for genetic evaluation of Swedish Standardbred trotters, and the BLUP indices are published in order to aid breeders in selection decisions. In addition to the 4 transformed racing performance traits described above (number of starts) ${ }^{1 / 2}$ and the all-or-none variable start status ( 1 if the horse had raced as 3-5-year-old; 0 if the horse had not raced as 35 -year-old) were included in the analysis. The basic linear mixed model was as follows in matrix notation:

$$
y=X \beta+Z a+e
$$

where $y$ is a vector of 6 racing variables on 40751 Standardbred trotters; $\beta$ is a vector of unknown fixed environmental effects (2 sexes $\times 16$ birth years); $a$ is a random vector for the traits included; $e$ is a random vector of residual effects. $X$ and $Z$ denote design matrices which assign fixed effects and animals, respectively, to the observed values. The standard assumptions are that $E(y)=X \beta, E(a)=E(e)=0$, $\operatorname{Var}(a)=G, \operatorname{Var}(e)=R$, and $\operatorname{Cov}\left(a, e^{\prime}=0\right)$.

Consequently $\operatorname{Var}(y)=Z G Z^{\prime}+R$. The relationship between 135120 animals was obtained through very complete pedigree ties covering on average 7 generations from the youngest animals to the base animals. Therefore $G=A \otimes$ $G_{0}$, where $A$ is the numerator relationship matrix and $G_{0}$ is the additive genetic (co)variance matrix of the racing variables. Furthermore $R=I \otimes R_{0}$, where $R_{0}$ represents the residual (co)variance matrix for the racing variables, $I$ is an identity matrix and $\otimes$ denotes the Kronecker product.

The Henderson's mixed model equations were solved by the indirect approach of Schaeffer \& Kennedy (1986). The official BLUP index is a weighted function of genetic evaluations for the 6 racing variables, scaled to a mean of 100 for a defined rolling base. In the index the genetic evaluations of number of starts are weighted by 0.05 , genetic evaluations of start status are weighted by 0.20 , and the remaining weight of 0.75 is given to the mean genetic evaluation of the racing performance variables: \% placed $1-3$, earnings and earnings per start. The BLUP index values for the POF-group of horses were compared with the contemporaries by a simple $t$ test for known variance.

\section{Frequencies of blood types}

In an evaluation of genetic determinants for POF the frequencies of blood types in 124 unrelated horses in the operated POF-group were compared to the frequencies in the population of Swedish Standardbred trotters. The population frequencies were calculated from a random sample of 1366 Standardbred trotters, born 1982-1986. The gene frequencies for this sample are similar to the gene frequencies for Swedish Standardbreds, which were calculated in 1974 (Sandberg 1974).

The analysis of the systems has been performed by standard methods used at the Blood group laboratory, Department of Animal Breeding and Genetics, Swedish University of Agricultural Sciences, Uppsala. The 14 blood type systems include red cell antigens (blood group) and variants of blood proteins. The blood group factors are analysed by means of immunological reactions and the blood proteins by gel electrophoresis, where different protein molecules are separated on a starch gel according to net charge, size and shape. The genetic marker systems used are D, K, A, Q, Ca, Pb, Tf, Es, Al, Hb, PGD, PGM, AP, PHI (for further description see: Sandberg \& Andersson 1984, Bowling \& Clark 1985), which have between 2 and 6 alleles. The first 6 are blood group systems, the following 8 are proteins and enzymes in serum and red cell lysate.

The blood group systems $\mathrm{C}$ and $\mathrm{K}$ are simple 
1-factor, 2-allele systems, and their allele frequencies were calculated by the square-root method. Of the complex systems A, D, P and Q, which comprise several factors, the allele frequencies were estimated as follows: $\mathbf{P}$ with Bernstein's equation developed for human $\mathrm{ABO}$; $\mathrm{A}$ and $\mathrm{Q}$ with the square-root method to obtain frequencies of the null alleles followed by calculation and adjustment of the other allele frequencies to obtain the best fit to the data under the assumption of Hardy-Weinberg's equilibrium; $D$ by direct counting assuming no ambiguous phenotypes. The estimation of allele frequencies in the protein systems was done by direct counting from phenotypes. The marker loci are considered to be independent of each other in hereditary transmission except for some slight linkage between $\mathrm{K}$ - PGD and Al Es systems (Sandberg \& Andersson 1992), but this is not considered to bias the present results. To study if any genetic difference may exist between the group of horses with POF and the total population, a homogeneity $\chi^{2}$-test on allele frequencies in these genetic blood marker systems was performed.

\section{Results}

Anatomical localisation of POFs

The $\chi^{2}$-analyses (Table 1 ) on the location of POFs showed that POFs in this study were most frequently located in hindlegs, and that they appear more often medially than laterally in the joints. Also the analysis showed no difference in localisation between left and right legs.

Bilateral fragments in the same joint were present in $19.5 \%$ of the 133 horses.

Sex

Of the 133 horses operated due to POFs, 69 were stallions/geldings and 64 were mares. There was no difference in frequency of POFs between sexes.

Age

Age (years) when surgery was performed:

1: 24 horses; 2: 53 horses; 3: 25 horses; 4: 13 horses; 5: 12 horses; 6: 3 horses; 7: 3 horses. $102(77 \%)$ of the horses had surgery performed during the first 3 years of age.

The majority of the 1- and 2-year-old horses did not show any lameness associated with their

Table 1. Anatomical location of POF.

\begin{tabular}{lccccc}
\hline Location & Medial & Lateral & Total & d.f. & $\chi^{2}$ \\
\hline Right fore & 2 & 1 & 3 & & \\
Left fore & 0 & 1 & 1 & & \\
Right hind & 54 & 21 & 75 & & \\
Left hind & 62 & 17 & 79 & & $38.5^{* * * *}$ \\
Total & 118 & 40 & 158 & 1 & \\
Percent & $74.6 \%$ & $25.4 \%$ & $100 \%$ & & \\
Hind leg & 154 & $97.5 \%$ & & & $142.4^{* * *}$ \\
Fore leg & 4 & $2.5 \%$ & & 1 & \\
Right leg & 78 & $49.4 \%$ & & & $0.03 \mathrm{~N} \mathrm{~S}$. \\
Left leg & 80 & $50.6 \%$ & & 1 & \\
\hline
\end{tabular}

*** $\mathrm{p}<0.001$.

N S. non-significant. 


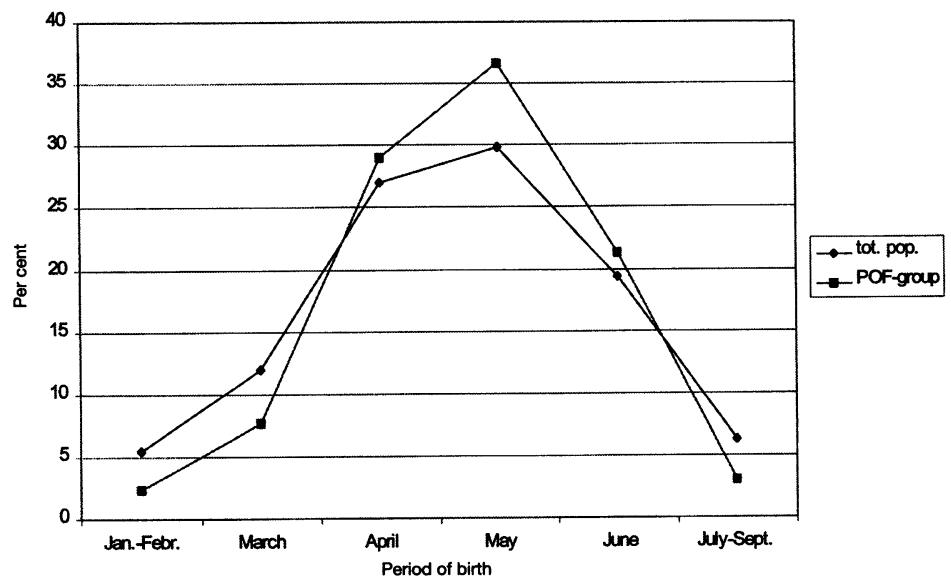

Figure 2. Periods of birth in the POF-group and the population of Swedish Standardbreds.

POFs. They were radiologically examined as a part of a purchase examination or because the owners wanted a check-up before start of training. In most of the older horses, 3 years or older, the POFs were considered by the referring veterinarians to be related to lameness in the fetlock joint where the fragment/s were located.

\section{Month of birth}

Horses with POFs and their months of birth were compared to the month of birth in the total population (Fig. 2).

There was a tendency towards a higher incidence of POF amongst horses born in AprilJune compared to horses born either early or late in the foaling season. This difference is not significant, however, for the sample included in this study. The results from the $\chi^{2}$ - analysis are shown in Table 2.

\section{Racing performance before/after surgical re- moval of POFs}

In the group of 133 POF-operated horses, 30 had started to race before the operation, and 24 of these 30 started after the operation (through
1994). The statistical analysis indicated that the means of annual performance index $I$ for POFhorses were the same before and after the POFoperation, and that the variances of these means were alike (Table 3 ).

103 horses in the POF-group had not started to race (most of them were 1-2 years old) before surgery. 69 of them (65\%) have completed a race through 1994. As a comparison, of all

Table 2. Horses with POF and their months of birth compared to the normal population (expected frequency).

\begin{tabular}{lcccc}
\hline $\begin{array}{l}\text { Period of } \\
\text { birth }\end{array}$ & $\begin{array}{c}\text { Expected } \\
\text { frequency }\end{array}$ & $\begin{array}{c}\text { Frequency } \\
\text { horses with } \\
\text { POF }\end{array}$ & d.f. & $\chi^{2}$ \\
\hline Jan-Febr. & 7.2 & 3 & 1 & 2.45 \\
March & 15.6 & 10 & 1 & 1.99 \\
April & 35.4 & 38 & 1 & 0.18 \\
May & 39.1 & 48 & 1 & 1.99 \\
June & 25.4 & 28 & 1 & 0.26 \\
July-Sept. & 8.2 & 4 & 1 & 2.16 \\
Total & 131 & 131 & 5 & 9.03 \\
\hline
\end{tabular}

$\mathrm{p}=0.05,1$ degree of freedom $\chi^{2}=3.85$.

$\mathrm{p}=0.05,5$ degree of freedom $\chi^{2}=11.10$. 
Table 3. Statistical comparison of racing performance as measured by annual performance index I, before and after POF-operation.

\begin{tabular}{lrccc}
\hline \multirow{2}{*}{ Time } & \multicolumn{3}{c}{ Annual performance index } & \\
\cline { 2 - 4 } & $\mathrm{N}$ & Mean & SD & Students $t$ test \\
\hline Results before op. & 16 & 105.50 & 8.91 & \\
Results after op. & 175 & 105.08 & 7.87 & $t=0.053$ N S. \\
\hline
\end{tabular}

5283 registered Swedish Standardbreds born in 1988,3077 (58\%) had completed at least one race through 1994.

\section{Comparison of BLUP values}

The BLUP values for the 133 horses in the POF-group were compared with the average value in the total population of Swedish Standardbreds of the same age as the POF horses. The BLUP values are unbiased and adjusted for year of birth and sex effects. In this group of POF horses, the mean variance of a single estimate around the true value was 56 units. The average BLUP value of the POF group was 103.4 ( \pm 0.65), while the population mean BLUP value of contemporaries was 98.9. Based on simple t-test related confidence limits this deviation is highly significant.

\section{Homogeneity test of allele frequencies in blood} type systems

The gene frequencies in the POF-group differ significantly from those in the Standardbred population for 2 of the 14 marker systems (table 4). This is enough to make the total comparison, where all markers are pooled, significant. The homogeneity test included 6 alleles in both the $\mathrm{D}$ and $\mathrm{Tf}$ systems, but the heterogeneity was confined to the $\mathrm{D}^{\mathrm{cg}}$ allele in the $\mathrm{D}$ locus $(0.484$ in the POF group versus 0.393 in the Standardbred population) and to $\mathrm{Tf}^{\mathrm{c}}$ in the $\mathrm{Tf}$ locus ( 0 in the POF group versus 0.034 in the Standardbred population).

\section{Discussion}

The high incidence of POFs in the Standardbred population is well known to most people involved in Standardbred breeding and racing. However, the clinical significance of these fragments has been disputed, especially if they are found in yearlings or in 2-year-old horses not showing any lameness, joint swelling or other discomfort in the joint. In spite of absence of clinical symptoms in these young horses many breeders and horse owners want the fragments surgically removed immediately because other-

Table 4. Homogeneity test of allele frequencies in blood type systems for horses with POF and the population of Swedish Standardbred trotters.

\begin{tabular}{lcc}
\hline Blood type & $\begin{array}{c}\text { Degree of } \\
\text { freedom }\end{array}$ & $\chi^{2}$ \\
\hline $\mathrm{D}$ & 5 & $18.34^{* *}$ \\
$\mathrm{~K}$ & 1 & 0.69 \\
$\mathrm{~A}$ & 2 & 0.10 \\
$\mathrm{Q}$ & 3 & 1.07 \\
$\mathrm{Ca}$ & 1 & 3.26 \\
$\mathrm{~Pb}$ & 1 & 1.27 \\
$\mathrm{Tf}$ & 5 & $13.01^{*}$ \\
$\mathrm{Es}$ & 2 & 4.63 \\
$\mathrm{Al}$ & 2 & 4.36 \\
$\mathrm{Hb}$ & 1 & 0.00005 \\
$\mathrm{PGD}$ & 1 & 0.19 \\
$\mathrm{PGM}$ & 2 & 1.65 \\
$\mathrm{AP}$ & 1 & 0.14 \\
PHI & 1 & 0.53 \\
Total & 28 & $49.24^{* *}$ \\
\hline${ }^{*} \mathrm{p}<0.05$. & & \\
${ }^{* *} \mathrm{p}<0.01$. & & \\
\end{tabular}


wise they cannot sell the horse. Horse buyers often raise questions to the veterinarian if POFs found in young horses at purchase examination are likely to affect the future racing capacity and if it is recommended to buy a horse with POFs. This type of question is not easy to answer due to the uncertainty of the clinical significance. In some cases the POFs obviously do not have any negative effect, as there are a number of breeding stallions with POFs that have successfully competed at the highest international level. In other cases, horses have shown lameness from their fetlock joints where POFs are present and the lameness disappears after intraarticular anaesthesia. The question then is if it is the POF or some other etiological factor involved that is causing the lameness. Clinical experience has shown that in most cases when the POFs have been surgically removed the horse has become sound and returned to earlier racing capacity, which also was shown in the present study.

The 133 horses operated for POFs in this study were horses selected from the normal caseload at the clinic. All horses that were operated for POFs during the period of study were included in the study. This material is selected in that owners or trainers have considered the cost worthwhile to operate these horses.

Complete clinical data prior to surgery have not been possible to record because many of the horses in this study were clinically examined elsewhere and then referred to the clinic specifically for arthroscopic surgery.

The distribution of sex and anatomical localisation of the POFs in this material were in agreement with earlier studies (Roneus \& Carlsten 1989, Gröndahl 1992, Sandgren et al. 1993).

The evaluation of the breeding index, BLUP, shows that horses with POFs in this study have a significantly higher mean value than the mean of the total population. This result indicates that this group of horses belongs to the "best" horses in the population. This may be because horses referred for surgery are a selected group with owners who are prepared to spend money for surgery because of good genetic background, or are older horses that have already shown good training and racing performance. In horses that had raced successfully before surgery and where the surgery was performed due to later onset of lameness associated with POFs, the result shows that after surgery the horses became sound and raced on the same level as before surgery. Generally the POFs did not seem to reduce the racing capacity of the horses. This is an important finding for the prognosis of an otherwise sound horse considered for purchase.

Another important finding is that for the horse with lameness related to the POFs the prognosis for soundness and return to earlier racing capacity was found to be favourable after arthroscopic removal of the fragments.

All horses were operated with arthroscopic surgery, which in our clinic during the last 10 years have been the routine method in removing POFs. A single POF in a joint is easy to remove, but bilateral fragments in the same joint take some practice to remove without changing the arthroscopic portal or turning the horse over to the other side. All horses were recommended a convalescence period of 6 weeks' rest in a box and daily hand walking. Maybe the convalescence period could be shortened as the joint cartilage of the third metacarpal- or metatarsal bone, the first phalanx or the sesamoid bones in most cases are not traumatised during the arthroscopic procedure, as the POFs are embedded in the fibrous joint capsule with only one surface facing the joint space. No adverse reactions secondary to the surgical procedure were seen in any of the 133 horses, indicating that the technique used was nontraumatic and safe.

Previous studies by Carlsten et al. (1993) 
showed that POFs develop early in life and can in most cases be radiologically detected before the age of 5 months. The etiological theory has proposed that biomechanical stress to the fetlock, especially high tension loads in the short sesamoidean ligaments inserting into tissue with osteogenic properties causes the tissue to be avulsed from the first phalanx, is a contributing factor for the development of POFs (Dalin et al. 1993). If this theory is correct, early physical activity in life could provoke the development of the fragments and therefore the month of birth may be of importance for the incidence. Philipsson et al. (1993) found in a population of 145 horses with POFs a significantly higher incidence of POFs in horses born in the summer (June-August) compared to horses born in the spring (February-April). A similar tendency was found in this study of 133 horses, but the highest incidence was found in horses born in April-June compared to horses born either early or late in the foaling season. This tendency was not statistically significant.

Mostly associations to marker loci for complex traits are due to linkage disequilibrium between the alleles at a marker locus and a nearby locus that influences the trait. Rarely the marker locus itself contributes to the variation in the trait under observation. The D system affects the morphology of red blood cells, whereas the Tf system contributes to the iron transport in blood. Tf is among the most informative serum protein systems that discriminate between groups of horses (Sandberg 1974) and primates (Manis 1993), and may therefore be of interest. Further investigations in gene frequencies of blood marker systems, their discriminating strength, and the genetic distance between POF-groups and the normal population of Standardbreds are necessary for a final statement of the genetic background to POF.

\section{References}

Arnason T, Darenius A, Philipsson J: Genetic selection indices for Swedish trotter broodmares. Livest. Prod. Sci. 1982, 8, 557-565.

Arnason T: The importance of different traits in genetic improvement of trotters. Proc. 5th World Congress on Genetics Applied to Livestock Production. 1994, 17, 462-470.

Birkeland R: Chip fractures of the first phalanx in the metatarsophalangeal joint of the horse. Acta Radiol. (Suppl.). 1972, 319, 73-77.

Bowling AT, Clark RS: Blood group and protein polymorphism gene frequencies for 7 breeds of horses in the United States. Animal Blood Groups and Biochemical Genetics, 1985, 16, 93-108.

Carlsten J, Sandgren B, Dalin G: Development of osteochondrosis in the tarsocrural joint and osteochondral fragments in the fetlock joints of standardbred trotters. I. A radiological survey. Equine Vet. J. Suppl. 1993, 16, 42-47.

Dalin G, Sandgren B, Carlsten J: Plantar osteochondral fragments in the fetlock joints of Standardbreds; result of osteochondrosis or trauma? Equine Vet. J. Suppl. 1993, 16, 62-65.

Gröndahl AM: The incidence of bony fragments and osteochondrosis in the metacarpo- and metatarsophalangeal joints of standardbred trotters. A radiographic study. J. Equine Vet. Sci. 1992, 12, 8185.

Henderson $C R$, Quaas $R L$ : Multiple trait evaluation using relatives' records. J. Anim. Sci. 1976, 43, 1188-1197.

Houttu J: Arthroscopic removal of osteochondral fragments of the palmar/plantar aspect of the metacarpo/metatarsophalangeal joints. Equine Vet. J. 1991, 23, 163-165.

Manis GS: A simple method for genetic typing of transferrins in nonhuman primates. Biotechniques, 1993, 15, 852-855.

McIlwraith $C W$ : Diagnostic and surgical arthroscopy in the horse. Sec. ed., Lea \& Febiger, Philadelphia, London. 1990.

Philipsson J, Andrèasson E, Sandgren B, Dalin G, Carlsten $J$ : Osteochondrosis in the tarsocrural joint and osteochondral fragments in the fetlock joints in standardbred trotters. II Heritability. Equine vet. J. Suppl. 1993, 16, 38-41.

Roneus B, Carlsten J: Lösa benbitar i kot-omhasleder hos unga travhästar. (Osteochondral fragments in fetlock and tarsal joints in young standardbred tratters). Svensk Veterinärtidning 1989, 41, 7, 417-422. 
Sandberg K: Blood typing of horses: Current status and application to identification problems. Proc. 1 :st World Congr. on genetics applied to livestock production, Madrid. 1974.

Sandberg $K$, Andersson L: Genetic linkage in the horse. I. Linkage relationships among 15 blood marker loci. Hereditas, 1984, 100, 199-208.

Sandberg K, Andersson L: Horse (Equus Caballus). In: Genetic Maps, sixth ed., S. J. O'Brien, Ed. Cold Spring Laboratory Press, New York. 1992, 4276-4278.

Sandgren B: Bony fragments in the tarsocrural and metacarpo-metatarsophalangeal joints in the standardbred horse - a radiographic survey. Equine Vet. J. 1988, Suppl. 6, 66-70.

Sandgren B: Osteochondrosis in the tarsocrural joint and osteochondral fragments in the metacarpo/metatarsophalangeal joints in young Standardbreds. Faculty of Veterinary Medicine, Swedish University of Agricultural Sciences, Uppsala, Sweden, Thesis, 1993.

Schaeffer LR, Kennedy BW: Computed strategies for solving mixed model equations. J. Dairy Sci. 1986, 69, 575-579.

Sönnichsen HV, Kristoffersen J, Falk-Rönne J: Joint mice in the fetlock joint - osteochondritis dissecans. Nord. Vet. Med. 1982, 34, 399-403.

\section{Sammanfattning}

Lösa benfragment (POF) $i$ kotleder hos travhästar. Resultat av kirurgiskt avlägsnande med artroskopiteknik samt analys av möjlig genetisk bakgrund.

133 varmblodiga travhästar med lösa benfragment palmart/plantart i kotleden (POF, palmar/plantar osteochondral fragment) studerades. Hos samtliga hästar avlägsnades fragmenten med artroskopiteknik. 102 av hästarna var 3 år eller yngre då operationen utfördes. Den anatomiska lokalisationen överensstämde med tidigare rapporter. Det förelåg ingen signifikant skillnad $\mathrm{i}$ födelsemånad mellan POF-hästarna jämfört med hela populationen. $80 \%$ av de hästar som tävlat $i$ lopp före operationen tävlade efter operationen och deras tävlingsresultat låg på samma nivå som före operationen. $65 \%$ av de hästar som inte tävlat före operationen kom till start efter operationen. Avelsindex BLUP (Best Linear Unbiased Prediction) användes för att utvärdera om POF-hästarna genetiskt skilde sig från totalpopulationens tävlingsresultat. Medelvärdet på BLUP för POF-hästarna var $103.4( \pm 0.65)$ medan totalpopulationens BLUP-värde var 98.9. Denna skillnad var signifikant. Ett homogenitetstest av allelfrekvenserna i olika blodgrupps-och proteinsystem utfördes för att utröna om det förelåg genetiska skillnader mellan POF-hästarna och den totala populationen. Statistisk analys av genfrekvenserna visade genetisk heterogenitet för blodgruppssystem $\mathrm{D}$ och proteinsystem $\mathrm{Tf}$.

(Received September 11, 1996; accepted September 18, 1997).

Reprints may be obtained from: Department of Surgery and Medicine, Large Animals, Box 7018, Swedish University of Agricultural Sciences, 75007 Uppsala, Sweden, tel: +46186710 00, fax: +4618672919. 